\title{
Primary Small Lymphocytic Lymphoma of the Renal Capsule: A Histopathological Case Report \\ Hristo Popov ${ }^{1}$, Ina Kobakova ${ }^{1}$, George S. Stoyanov ${ }^{1}$
}

1. General and Clinical Pathology, Forensic Medicine and Deontology, Medical University of Varna, Varna, BGR

Corresponding author: George S. Stoyanov, georgi.geesh@gmail.com

\begin{abstract}
Lymphomas are one of the most common malignant entries across all populations. Originating most commonly from the lymph nodes, extranodal lymphomas, including those originating from the connective tissue capsule of the internal organs, are rare entries. Herein we present a case report of a 78-year-old male patient presenting with a palpable mass in the region of the left kidney. Ultrasound and computer tomography revealed a mass engulfing the kidney. Nephrectomy was performed, with the histopathological investigation revealing a non-Hodgkin lymphoma originating from the renal capsule, with infiltration into the adjacent tissues. The patient was referred to a hematologist for treatment and one and a half years later, following two negative bone marrow biopsies, the patient is alive and disease-free.
\end{abstract}

Categories: Pathology, Urology, Hematology

Keywords: primary renal lymphoma, hematology, small lymphocytic lymphoma, pathology

\section{Introduction}

Lymphomas are consistently cited as amongst the top 10 most common malignancies, with increasing incidence worldwide $[1,2]$. Originating primarily from the lymph nodes, tonsils, and mucosa-associated lymphoid tissue, lymphomas can also seldom originate as primary lesions in parenchymal organs such as the spleen and liver and more rarely in the lung and central nervous system.

Primary lymphoma of the connective tissue capsule of parenchymal organs is an extremely rare finding and can often be interpreted as a sign of infiltration or a soft tissue sarcoma [3].

\section{Case Presentation}

Herein we report the findings in a 78-year old male. The patient presented with a palpable mass in the left renal region, without any further complaints such as pain, hematuria, and weight loss. An ultrasound and computer tomography scan showed a large formation in the renal capsule (Figure 1). Concomitant diseases and past medical history included four traumatically fractured ribs, healed without complications,

Received 12/16/2019

Review began 12/16/2019 Review ended 12/18/2019 Published 12/20/2019

(c) Copyright 2019

Popov et al. This is an open access article distributed under the terms of the Creative Commons Attribution License CC-BY 3.0., which permits unrestricted use, distribution, and reproduction in any medium, provided the original author and source are credited. hypertension, angina pectoris, and an aortocoronary bypass.

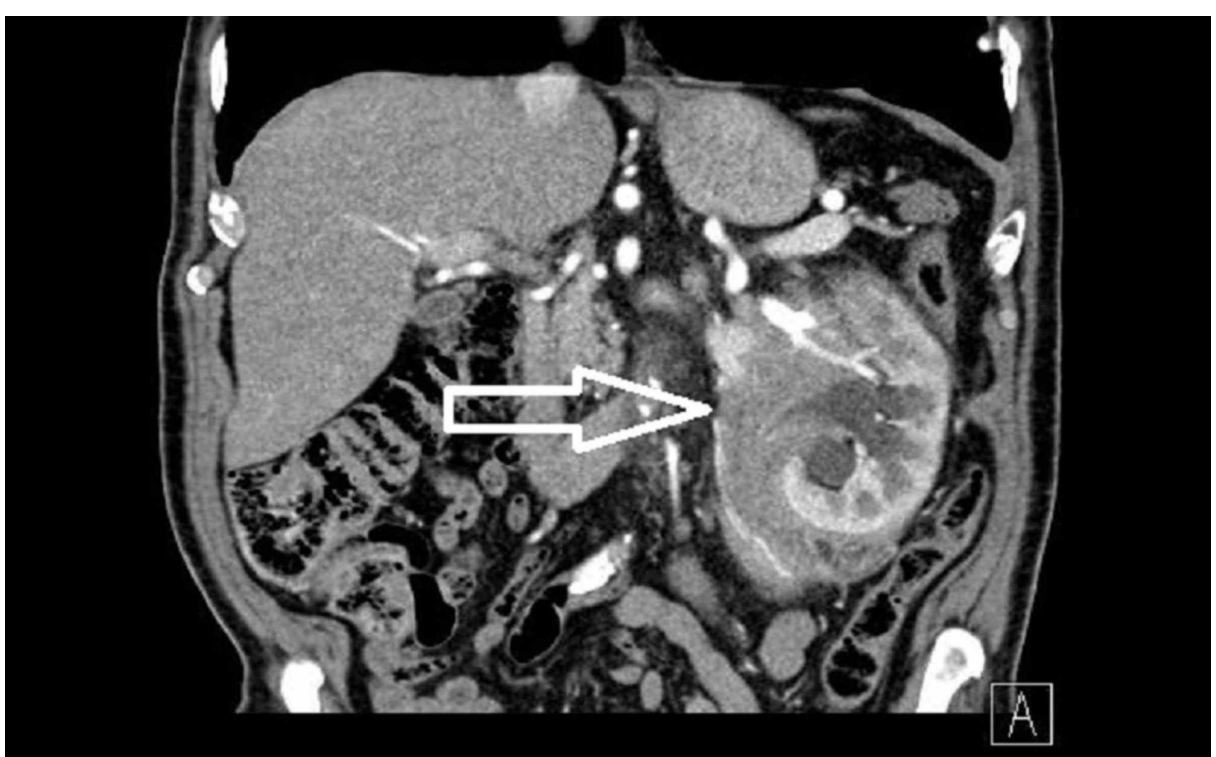

FIGURE 1: Computed tomography finding (arrow) 


\section{Cureus}

An endoscopic nephrectomy approach was chosen. The procedure was carried out under general anesthesia. An additional renal artery and vein were located in the inferior pole and after their ligation and separation, the principal renal artery and vein were ligated and separated. An extended resection was performed with full ureter resection and partial resection of the urinary bladder. The kidney along with its capsule was then dissected and explanted through a subcostal incision.

The materials were sent for histopathological evaluation. The total specimen measured $17 / 10 \mathrm{~cm}$, of which the kidney specimen measured $12 / 7 \mathrm{~cm}$ and the adjacent pale and solid tumor tissue measured $10 / 1.5 \mathrm{~cm}$ (Figure 2). The adjacent ureter had a length of $15 \mathrm{~cm}$. The specimens were fixed in $10 \%$ neutral-buffered formaldehyde and embedded in paraffin (FFPE) for staining with hematoxylin and eosin (H\&E) and immunohistochemistry (IHC).

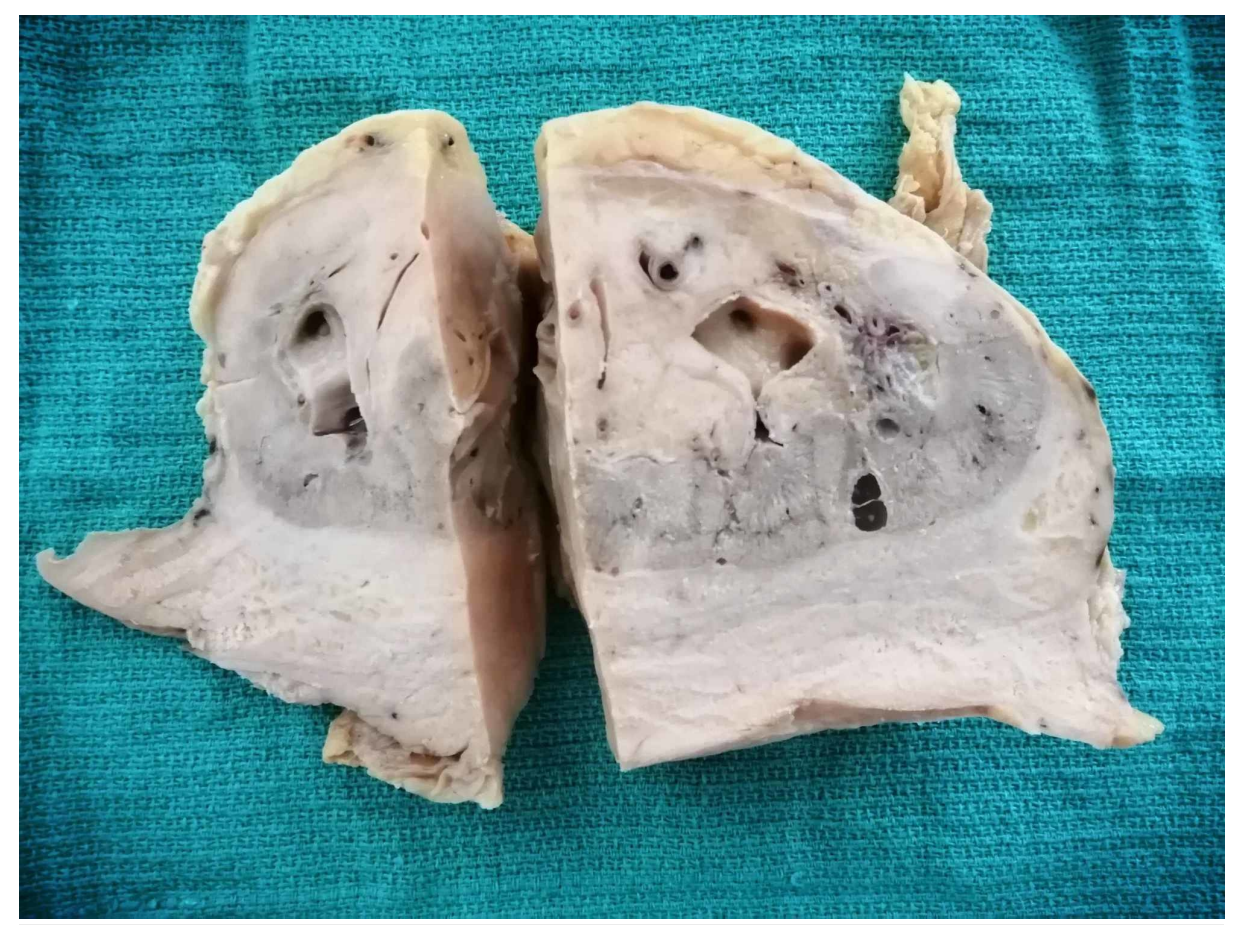

\section{FIGURE 2: Gross view of the specimen}

The FFPE tissue sections stained with H\&E showed nodular structures comprised of small to medium-sized atypical monomorphous lymphoid cells with formation of pseudofolicles. The tumor originated from the renal capsule and infiltrated the kidney, adjacent adrenal gland capsule, renal hilar vessels, and proximal part of the ureter, without infiltration into its distal part and the accessory renal vessels (Figures 3, 4). The adjacent perirenal lymph nodes were not involved in the process. The tumor cells were showed a positive cytoplasmic B-cell lymphoma 2 (Bcl2), and a membranous cluster of differentiation 3 (CD3), CD5, CD20, CD23, and CD43 IHC reaction (Figure 5). The tumor cells were negative for Cyclin D1 and Bcl6, whilst CD10 and $\mathrm{CD} 30$ reacted only with a small number of scattered cells within the tumor sample. The Ki-67 index for positive nuclei amounted to $30 \%$. 


\section{Cureus}

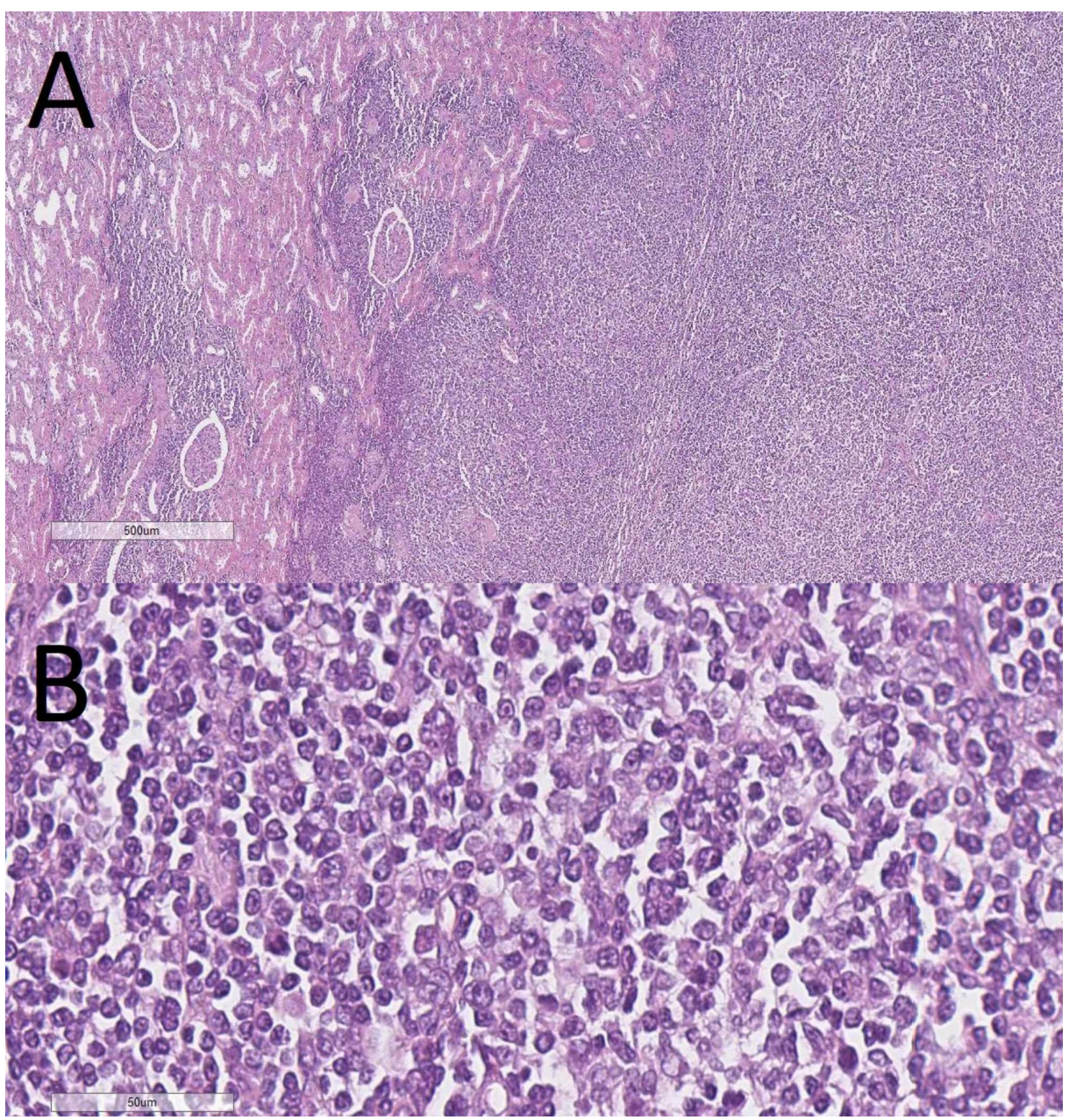

FIGURE 3: Lymphocytic proliferation in the renal capsule with infiltration into the parenchyma, H\&E stain, (A) original magnification 40x, (B) original magnification $400 x$

H\&E: hematoxylin and eosin 


\section{Cureus}

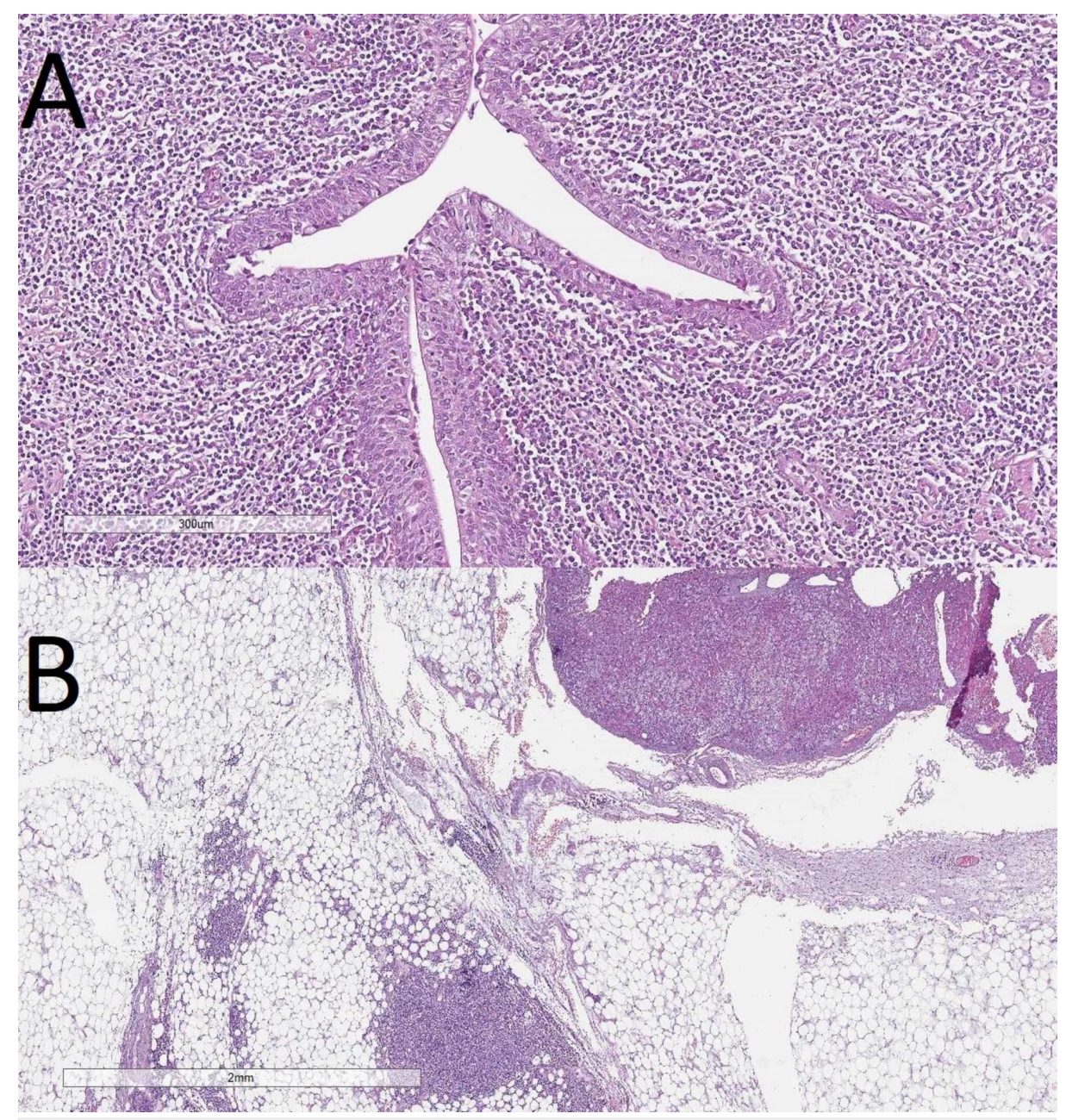

FIGURE 4: (A) Invasion into the proximal part of the ureter, H\&E, original magnification 100x. (B) Invasion into the periadrenal connective tissue, $H \& E$, original magnification $20 x$

H\&E: hematoxylin and eosin 


\section{Cureus}

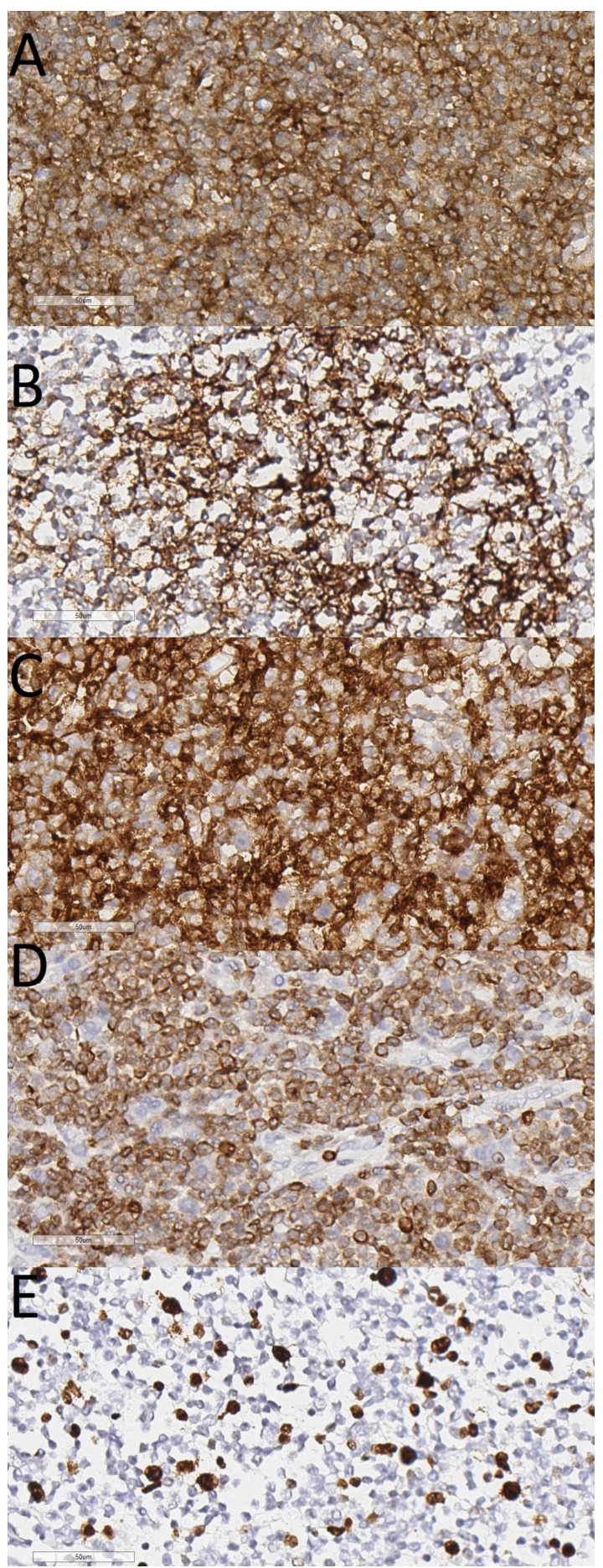

FIGURE 5: IHC profile (A) CD43, original magnification 400x; (B) CD23, original magnification 400x; (C) CD5, original magnification 400x; (D) $\mathrm{BCL2}$, original magnification 400x; (E) Ki-67, original magnification 400x IHC: immunohistochemistry; CD: cluster of differentiation; BCL2: B-cell lymphoma 2

Despite the casuistical origin, based on the lack of other affected structures and both the H\&E tumor sample and the reactions with the IHC panel, the diagnosis of small lymphocytic lymphoma was accepted.

The postoperative period was uneventful. The patient was referred to a hematologist for treatment and subsequent reevaluation. Two additional bone marrow biopsies were performed, with no evidence for bone marrow invasion by the process. One and a half years postoperatively, the patient is alive and disease-free. 


\section{Discussion}

Hematological malignancies require deep-rooted knowledge for their interpretation and a wide set of IHC markers. In the case of extranodal lymphomas, the interpretation is even more difficult, and the histology needs to be interpreted together with the radiological findings and the patient's clinical data to differentiate from infiltration from a nodal lymphoma [4].

In such cases, a bone marrow biopsy should also be performed to evaluate the progression of the disease and also rule out leukemia with infiltration into the parenchymal organs.

Differential diagnosis with small round blue cell tumors, more often originating from the kidney and perirenal tissue should also be kept in mind, which further prioritizes the use of IHC [5,6]. These tumors include all types of soft tissue sarcomas, and the undifferentiated types among them, such as liposarcoma and rhabdomyosarcoma, may mimic the histological profile of lymphoma. In male patients, they also mimic germ cell tumors that originate from an undescended testis.

The value of IHC in such cases is unquestioned as, despite the similarities in the histological profile, the IHC reactions are specific for the separate groups of tumors such as CD20 for B-cell lymphomas, OCT3/4 in germ cell tumors, and S100 in soft tissue sarcomas.

The kidneys, however, are the most common site of extranodal lymphomas, although most commonly affected as a secondary site [7]. As such special emphasis should always be placed on renal lymphoma, and especially a multidisciplinary approach should be taken in such patients to differentiate between a primary entry and secondary involvement [7].

\section{Conclusions}

Primary lymphoma of the renal capsule is a rare condition, requiring a wide set of IHC markers and interpretation together with the radiological finding, clinical data, and bone marrow biopsy to differentiate it from nodal lymphoma infiltration and small round blue cell neoplasms.

\section{Additional Information \\ Disclosures}

Human subjects: Consent was obtained by all participants in this study. Conflicts of interest: In compliance with the ICMJE uniform disclosure form, all authors declare the following: Payment/services info: All authors have declared that no financial support was received from any organization for the submitted work. Financial relationships: All authors have declared that they have no financial relationships at present or within the previous three years with any organizations that might have an interest in the submitted work. Other relationships: All authors have declared that there are no other relationships or activities that could appear to have influenced the submitted work.

\section{References}

1. Smith A, Crouch S, Lax S, et al.: Lymphoma incidence, survival and prevalence 2004-2014: sub-type analyses from the UK's Haematological Malignancy Research Network. Br J Cancer. 2015, 112:1575-1584. 10.1038/bjc.2015.94

2. Chen J, Peng J, Zheng Y, et al.: Primary renal lymphoma: a population-based study in the United States, 1980-2013. Sci Rep. 2019, 9:15125. 10.1038/s41598-019-51635-6

3. Shetty S, Singh AC, Babu V: Primary renal lymphoma: a case report and review of literature . J Clin Diagnostic Res. 2016, 10:5-7. 10.7860/JCDR/2016/20901.8577

4. Xiang H, Zhong W, Gao Q, Bai Y, Wang Z: Primary renal non-Hodgkin's lymphoma: a clinicopathologic study of six cases and review of the literature. Int J Clin Exp Pathol. 2016, 9:7436-7443.

5. Celik A, Yildiz Y, Özekinci S, Mizrak B: Non-Hodgkin's lymphoma of kidney presenting as a solid mass: case report. J Clin Exp Pathol. 2012, 2:117. 10.4172/2161-0681.1000117

6. Chen X, Hu D, Fang L, et al.: Primary renal lymphoma: a case report and literature review . Oncol Lett. 2016, 12:4001-4008. 10.3892/ol.2016.5173

7. Schniederjan SD, Osunkoya A: Lymphoid neoplasms of the urinary tract and male genital organs: a clinicopathological study of 40 cases. Mod Pathol. 2009, 22:1057-1065. 10.1038/modpathol.2009.65 